\title{
Assessing motivation to change in eating disorders: a systematic review
}

\author{
Katrin Hötzel ${ }^{1,2^{*}}$, Ruth von Brachel ${ }^{1,2}$, Lena Schlossmacher ${ }^{2}$ and Silja Vocks ${ }^{1}$
}

\begin{abstract}
Background: Patients with anorexia and bulimia nervosa are often ambivalent about their eating disorder symptoms. Therefore, a lack of motivation to change is a frequent problem in the treatment of eating disorders. This is of high relevance, as a low motivation to change is a predictor of an unfavourable treatment outcome and high treatment dropout rates. In order to quantify the degree of motivation to change, valid and reliable instruments are required in research and practice. The transtheoretical model of behaviour change (TTM) offers a framework for these measurements.

Objective: This paper reviews existing instruments assessing motivation to change in eating disorders.

Method: We screened $N=119$ studies from the databases Medline and Psycinfo found by combinations of the search keywords 'eating disorder', 'anorexia nervosa', 'bulimia nervosa', 'motivation', 'readiness to change', 'assessment', 'measurement', and 'questionnaire'.
\end{abstract}

Results: Ultimately, $n=15$ studies investigating psychometric properties of different assessment tools of motivation to change in eating disorders were identified. Reviewed instruments can be divided into those assessing the stages of change according to the TTM ( 6 instruments) and those capturing decisional balance ( 3 instruments). Overall, the psychometric properties of these instruments are satisfactory to good.

Discussion: Advantages, disadvantages, and limitations of the reviewed assessment tools are discussed. So far, the TTM provides the only framework to assess motivation to change in eating disorders.

Keywords: Anorexia nervosa, Assessment, Bulimia nervosa, Interview, Motivation to change, Questionnaire

\section{Introduction}

Patients with anorexia and bulimia nervosa are known to be ambivalent about their eating disorder symptoms [1]. On the one hand, the eating disorder is perceived as a burden, but on the other hand, it also provides reasons to hold on to it [2]. Consequently, patients with eating disorders often display a low motivation to change [3-5]. This low motivation to change is often viewed as the cause for the high dropout rates or lack of engagement which are major problems in the treatment of anorexia and bulimia nervosa [6,7]. Further indications of the high clinical relevance of motivation to change in eating disorders are provided by several studies suggesting a positive association between a high motivation to change

\footnotetext{
* Correspondence: katrin.hoetzel@ruhr-uni-bochum.de

'Department of Psychology, Clinical Psychology and Psychotherapy, Osnabrück University, Knollstraße 15, 49069, Osnabrück, Germany

${ }^{2}$ Department of Psychology, Clinical Child and Adolescent Psychology, Ruhr-University Bochum, Universitätsstraße 150, 44801, Bochum, Germany
}

and several desirable clinical indices (such as continuing treatment, decreases in eating pathology, increases in weight, and weight maintenance) [8-11]. Based on these results, several studies have been conducted in order to assess the effects of interventions aiming at an enhancement of motivation to change in eating disorders (for an overview, see [12]).

Given the high clinical relevance of motivation to change in eating disorders and the great interest in investigating this field, there is a need for appropriate psychometric assessment tools. Such tools could ensure a more uniform and valid methodology for future research [13]. Furthermore, as patients' and clinicians' perceptions of motivation to change have been shown to differ significantly [14] and clinicians' ratings have been shown to be unrelated to any outcome measures [15], specific and valid assessment tools are required not only for science, but also for clinical practice. Such instruments enable insights, for instance, 
into the patient's perception of benefits and burdens of a change [2] and in this respect help therapists to optimise the selection of treatment strategies for each patient.

Several measures to assess motivation to change have been developed, all of which are rooted in the transtheoretical model of behaviour change (TTM [16]), which represents the most common theoretical framework in this research area. The TTM offers an explanation for motivation to change in general and has been applied to several health problems and mental disorders, including eating disorders [13]. It defines 'stages' of readiness for change, which occur through a series of six motivational stages (i.e., precontemplation, contemplation, preparation, action, maintenance, and termination) and are characterised by various degrees of involvement in the therapeutic process. Furthermore, the TTM comprises a theory on decision making [17], which is considered to be a necessary process in order to progress through the stages. The decision making process depends on the balance of perceived pros and cons for a problem behaviour, which is also known as decisional balance (for a comprehensive review of the TTM, see [16]). Derived from these theoretical assumptions, instruments on motivation to change can be categorised into two groups: those assessing the stages of change and those capturing decisional balance.

To summarise, it can be stated that motivation to change is an important aspect of the treatment of eating disorders. The application of evaluated instruments which assess motivation to change in eating disorders is urgently required for research and practice. However, as yet to our knowledge, no review on instruments that measure motivation to change in anorexia and bulimia nervosa has been published. Therefore, the aim of the present paper is to review the existing instruments assessing motivation to change in eating disorders regarding their psychometric properties and to provide a critical evaluation of these tools.

\section{Method}

We selected studies from the databases Medline and Psycinfo by searching for the combined keywords 'eating disorder,' 'anorexia nervosa,' 'bulimia nervosa,' 'motivation', 'readiness to change, 'assessment', 'measurement', 'questionnaire', and 'interview' from February to March 2013. Five articles were added which were retrieved from references of included articles or were known of by the authors from other sources. Papers investigating the psychometric properties of assessment devices for motivation to change in eating disorders were included in this review. Furthermore, the papers had to be published in a peer-reviewed journal in the English language. We only included instruments for which information both on reliability and validity was published. Papers on instruments for which only information concerning validity was available were excluded, as reliability is considered as the precondition for all forms of validity [18]. Moreover, only studies which used eating disorder-specific questionnaires for the assessment of motivation to change were examined.

\section{Review}

Figure 1 presents a QUORUM diagram of the literature search. The final set of papers comprised $n=15$ papers.

Table 1 presents the identified papers on instruments specifically assessing motivation to change in eating disorders. The identified instruments differ according to whether they measure the stages of change or decisional balance. Furthermore, most of the instruments are questionnaires, while one is an interview. In the following section, the interview assessing the stages of change is introduced first; following this, questionnaires measuring the stages of change are presented. Finally, decisional balance scales are presented.

\section{Interview assessing the stages of change}

The Readiness and Motivation Interview (RMI $[19,20])$ is a semi-structured interview which contains several questions to assess motivation to change. The stages of change are measured according to four different symptom domains of the eating disorder (i.e., restriction, cognition, bingeing, and compensatory behaviour). If a patient is in the stage of action, the locus of control is also rated. As displayed in Table 1, reliability and validity are very good. In addition to adults, the $R M I$ has also been used in a younger population of 12-18-year-old girls with eating disorders [21].

\section{Questionnaires assessing the stages of change}

Further identified measurements of the stages of change according to the TTM are the Anorexia Nervosa Stages of Change Questionnaire (ANSOCQ [22,23]), the Bulimia Nervosa Stages of Change Questionnaire (BNSOCQ [25]), the Eating Disorders Stages of Change Questionnaire (EDSOCQ [26]), the Motivational Stages of Change for Adolescents Recovering from an Eating Disorder (MSCARED [27]), and the Readiness and Motivation Questionnaire (RMQ [28]). The ANSOCQ, BNSOCQ, EDSOCQ, and $R M Q$ assign a stage of change for each symptom domain of the eating disorder (e.g., gaining weight, importance of body shape and weight, fear of fatness). According to this conceptualisation, a person might, for example, be in the contemplation stage regarding her bingeing behaviour, but can simultaneously be in the precontemplation stage concerning her attempt to remain very thin. Unlike these four questionnaires, the MSCARED assesses the stages of change for adolescents currently recovering from an eating disorder in a global manner. With this measurement, the adolescent is allocated to one stage of change for the motivation to change the eating disorder as a whole. 


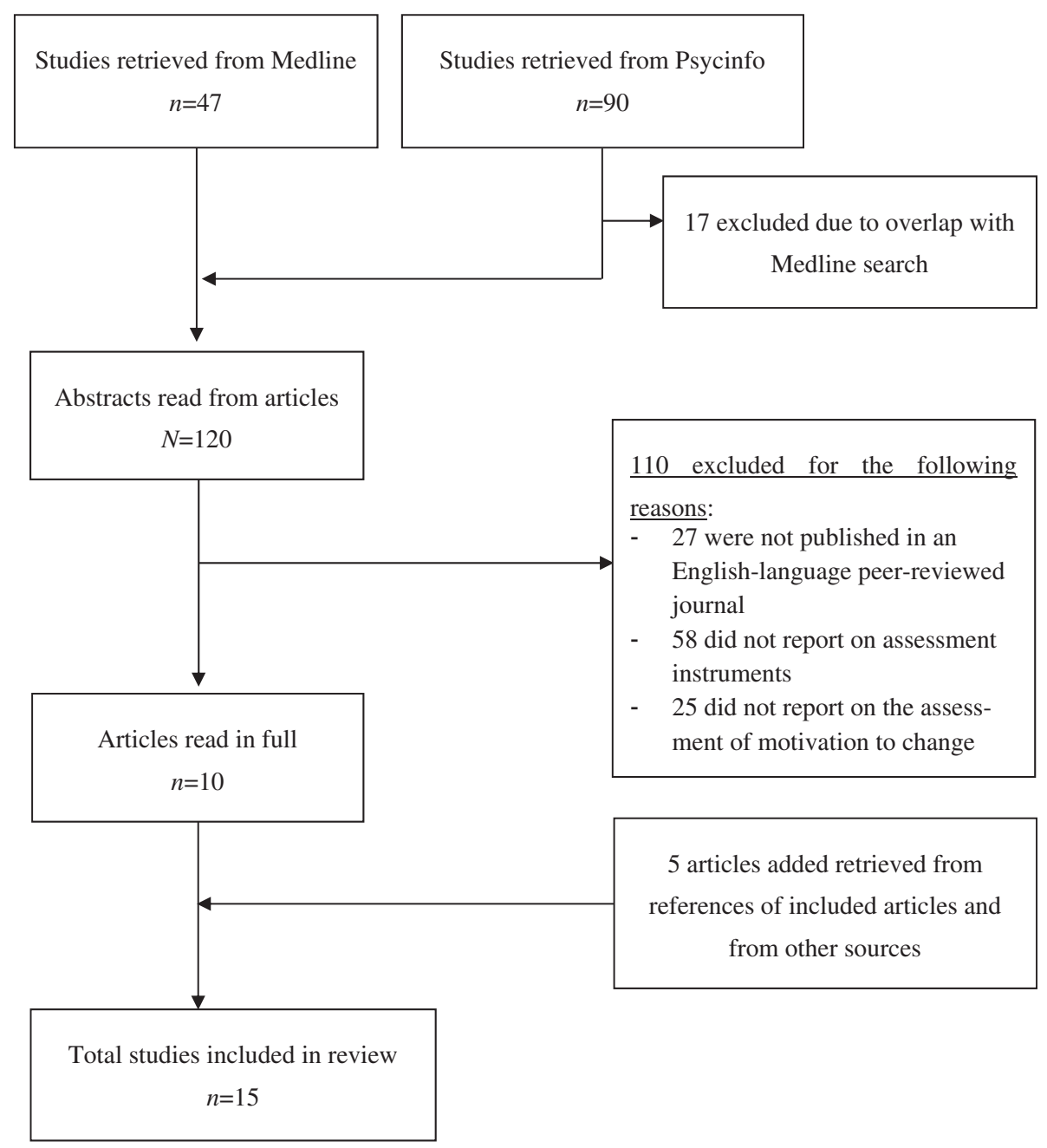

Figure 1 QUORUM diagram showing results of the literature search.

The ANSOCQ and BNSOCQ were designed for specific diagnostic groups, i.e., patients with anorexia and bulimia nervosa, respectively. The EDSOCQ, MSCARED, and $R M Q$ can be applied to patients with anorexia nervosa, bulimia nervosa, and eating disorder not otherwise specified. Psychometric properties of the ANSOCQ and EDSOCQ have been analysed both in adults and adolescents [22-24,26], while the psychometric properties of the BNSOCQ and MSCARED have been evaluated for adolescents only [25,27] and those of the RMQ for adults [28] only. As displayed in Table 1, reliability and validity of these four questionnaires are generally good.

\section{Decisional balance scales}

The literature search revealed two decisional balance scales for anorexia nervosa, the Decisional Balance Scale for Anorexia Nervosa $(D B[29,30])$ and the Pros and Cons of Anorexia Nervosa (P-CAN [31]). The DB assesses both the perceived 'Benefits' and 'Burdens' of anorexia nervosa (e.g., gains or losses for the self and significant others, self-approval, self-disapproval, approval and disapproval of others) as well as 'Functional Avoidance' (e.g., how the disorder prevents the individual from dealing with emotions). It was adapted from a scale by Rossi et al. [45], while the P-CAN was derived from an analysis of the themes endorsed by patients suffering from anorexia nervosa [46]. The $P-C A N$ gives insight into the perceived pros and cons of the individual's anorexia nervosa. As Table 1 shows, it has been successfully applied to both adult [31] and adolescent populations [32] and reliability as well as validity is sufficient.

To broaden the application of the P-CAN to individuals with bulimia nervosa, some subscales dealing with bingeing and purging were added to the Pros and Cons of Eating Disorders Scale (P-CED) and the term 'anorexia nervosa' was substituted by 'eating disorder' [33]. Although information on the reliability of the P-CED has not been published, it is nevertheless included here, as 
Table 1 Instruments measuring motivation to change in eating disorders

\begin{tabular}{lll}
\hline Name of instrument & $\begin{array}{l}\text { Validation Format } \\
\text { study }\end{array}$ & Subscales
\end{tabular}

Assessment of the stages of change according to transtheoretical model of behaviour change

Readiness and Motivation Interview $[19,20] \quad$ Semi-structured Four subscales:

for eating disorders (RMD)

interview

Two subscales:

recontemplation', 'Action' (as the internal consistency for 'Contemplation' and 'Internality' was unacceptably low)

Anorexia Nervosa Stages of Change Questionnaire (ANSOCQ) Self-report (20 items) and a totis regarded separately $N=71$

AN adults and adolescents (inpatients)

$N=99$

$\mathrm{AN}, \mathrm{BN}, \&$ EDNOS

adults (inpatients)

'Precontemplation', 'Contemplation',

'Action', 'Internality'

$N=65$

$A N, B N, \& E D N O S$

adolescents (inpatients

and outpatients) study

Reliability

Validity
$N=44$

AN adults and

adolescents (inpatients)

$N=70$

AN adolescents
$97.9 \%$

$a=.19-.79$

$r_{t t}=.89$

$a=.90$

Interrater

agreement:

$95.6 \%-$

$97.4 \%$

$a=.63-.84$

Interrater

agreement:

(1)

DV: Non-significant correlations with age, socio-economic status, BM and social desirability

PV: Significant correlations with anticipated difficulty of completing tasks related to eating disorder recovery ${ }^{b}$; prediction of completion of recovery activities

CV: Significant correlations with URICA negative correlations of ANSOCQ total score with EDI-2

DV: Non-significant correlations of ANSOCO total score with social desirability in adults ${ }^{a}$, but positive correlations with social desirability in adolescents ${ }^{\mathrm{e}}$

PV: Prediction of weight gain during treatment by ANSOCQ total score; significant correlations between ANSOCQ total score at commencement of treatment and EDI-2 at discharge

CV: Positive correlations of ANSOCQ total score with self-efficacy, DB subscale 'Burden', and negative correlations with DB subscales 'Benefits' and 'Avoidance Coping', and CSS total score

CV: Negative correlations of ANSOCQ total score with EDI-2 and BDI 
Table 1 Instruments measuring motivation to change in eating disorders (Continued)

(inpatients and

outpatients)

Bulimia Nervosa Stages of Change Questionnaire (BNSOCQ)

Eating Disorders Stage of Change (EDSOC)

Self-report questionnaire Each symptom domain is (8 items) regarded separately.
$N=145$

$A N, B N, \&$ EDNOS

adults and

adolescents (inpatients

and outpatients) $\begin{array}{ll}r_{t t}=.94 & \text { CV: Negative correlations of BNSOCQ } \\ a=.93 & \text { total score with BDI-2 and EDI-2 }\end{array}$

DV: Non-significant correlations of the BNSOCQ total score with BMl and illnes duration, but positive correlations with age

$r_{t t}=.55-1.00$ CV: Positive correlations of 'Restrict', 'Diet $a=.33-.78$ Pill Use', and 'Fast' with URICA

DV: Non-significant correlations with BMI but negative correlations of 'Fast', 'Restric', 'Purge', 'Laxative Use', and 'Diet Pill Use' with BSQ and positive correlations of 'Purge', 'Laxative Use' and 'Diet Pill Use' with age

CV: Positive correlations of the youth's

together with an is in action or maintenance phase,

AN, BN, \& EDNOS

self-reported stage of change with the interviewer's and the mother's; lower EDI-2 and $\mathrm{CDI}$ scores in higher phases

DV: Non-significant correlations with the diagnostic category, and with initial or final BMI levels

Readiness and Motivation Questionnaire (RMQ)

Self-report questionnaire Two motivational stage scores

$N=207$

$r_{t t}=.62-.81 \quad \mathrm{CV}$ : Positive correlations of EDI with

5 items for each of 12

('Precontem-plation', 'Action') for eact

AN, BN, \& EDNOS adults

$a=.55-.80$ symptom domains) of four symptom domains; locus of

(outpatients)

control ('Internality', 'Confidence')
'Precontemplation' and negative

correlations with 'Action' and 'Confidence'.

Significant correlations with URICA and RMI.

DV: Non-significant correlations with BMl

self-efficacy, and social desirability ${ }^{\text {a }}$

negative correlations of 'Confidence' with age

PV: Significant correlations with the

anticipated difficulty of recovery activities

and completion of recovery activities ${ }^{d}$ 
Table 1 Instruments measuring motivation to change in eating disorders (Continued)

'Burdens', 'Benefits', 'Functional

Avoidance'

[30]

Pros and Cons of Anorexia Nervosa scale (P-CAN)

Pros and Cons of Eating
Disorders scale (P-CED)

\section{Self-report Likert scale Six pro-scales:}

(50 items)
'Safe/Structured'; 'Appearance'; 'Fertility/ Sexuality'; 'Fitness'; 'Communicate Emotions/Distress'. 'Special/Skill'

Four con-scales:

'Trapped'; 'Guilt'; 'Hatred'; 'Stifles Emotions'
$[32]$
Self-report Likert scale
(72 items)
Subscales of P-CAN and four additional ones: pro-scales:

$N=80$

AN \& EDNOS adults

(outpatients)

$N=233$

AN adults (inpatients

and outpatients)

$r_{t t}=.60-.85$

CV: Positive correlations of 'Burdens' with

PCQ; non-significant correlations of 'Benefits'

and 'Functional Avoidance' with PCQ

DV: Non-significant correlations with social desirability ${ }^{\text {a }}$ socio-economic status, and BMl; significant correlations of 'Functiona Avoidance' with age

CV: Positive correlations of P-CAN pro-scales 'Appearance', 'Communicate Emotions/ Distress', 'Fitness', and 'Safe/Structured' with EDI; negative correlations of the P-CAN con-scale 'Hatred' with EDI

DV: Non-significant correlations of the P-CAN subscales with BMI

$a=.73-.97 \quad \mathrm{CV}$ : Positive correlations of the P-CAN pro-scales 'Communicate Emotions/Distress', 'Special', 'Safe/Structured' with EDE-Q global score; positive correlations of P-CAN con-scales with EDE-Q total score

DV: Non-significant correlations of P-CAN subscales with BMI

$N=202 \quad$ None past or current diagnosis reported of AN or BN adults (outpatients)

AN adolescents

outpatients)
DV: Significant differences between patients with AN and BN on P-CED subscales Safe/Structured' (AN > BN), 'Special/Skills' $(A N>B N)$, 'Fitness' (AN > BN), 'Fertility/ Sexuality' (AN > BN) 'Eat but Stay Slim' $(\mathrm{AN}<\mathrm{BN})$, 'Guilt' (AN > BN)

'Boredom'; 'Eat but Stay Slim';

con-scales: 'Negative Self-Image'.

'Weight and Shape'

Note. In all cases, test-retest reliability was measured after approximately one week. The following abbreviations are used: AN = anorexia nervosa; BDI II = Beck Depression Inventory [34]; BN = bulimia nervosa; BSQ = Body Shape Questionnaire [35]; CDI = Children's Depression Inventory [36]; CSS = Concerns about Change Scale [37]; CV = convergent validity; DV = divergent validity; EDE-Q = Eating Disorder Examination Questionnaire [38]; $\mathrm{EDI}=$ Eating Disorder Inventory [39]; EDI-2 = Eating Disorder Inventory-2 [40]; EDNOS = eating disorder not otherwise specified; PCQ = Processes of Change Questionnaire [41]; PV = predictive validity; $r_{\mathrm{tt}}=$ test-retest reliability. a measured with Balanced Inventory of Desirable Responding [42].

${ }^{b}$ measured with Anticipated Difficulty of Recovery Activities $[21,24]$

cmeasured with Completion of Recovery Activities [21,24].

dmeasured with Marlowe-Crowne Social Desirability Scale [43]

emeasured with Children's Social Desirability Scale [44].

measured with Self-Efficacy Scale for AN [22] 
its items are nearly identical to the $P$-CAN, whose reliability is considered sufficient.

\section{Discussion and conclusion}

The aim of the present paper was to review assessment tools for motivation to change in eating disorders. 15 studies on nine different assessment tools for motivation to change in eating disorders were included. We identified $n=6$ instruments assessing motivation to change according to the stages of change and $n=3$ instruments capturing decisional balance.

Those instruments measuring the stages of change provide different types of assessments, measuring the stages either globally, i.e., motivation to change the eating disorder as a whole (e.g., MSCARED), or in a symptomspecific manner, i.e. motivation to change bingeing (e.g., ANSOCQ or RMI). However, due to the complexity regarding the different symptom domains of an eating disorder, it might be inappropriate to allocate a person to a single global stage $[21,26,47]$, as a symptom-specific measure of the stages of change was found to explain more variance of a problem behaviour than a global-stage assessment [48]. For example, it was shown that the motivation to change bingeing behaviour as one symptom domain was uniformly high across individuals, while motivation to change dietary restriction as another domain was rather low $[21,49]$. These requirements are especially fulfilled by the interview $R M I[19,20]$ and the questionnaires such as the ANSOCQ [22,23], BNSOCQ [25], EDSOCQ [26], and $R M Q$ [28], which are more economical to apply. Thus, in some recent studies, possibly existing differences in specific symptom domains may have remained undetected due to the global assessment of motivation to change [3,50].

However, in some cases, there seems to be a disconnection between the approach of measuring motivation in a symptom-specific manner and the actual statistical analyses conducted with the medium over all heterogeneous symptom domains. Even though the items of the ANSOCQ and BNSOCQ assess multiple dimensions of motivation to change, there are no separate subscales providing scores for each symptom domain, and instead, a global total score is calculated. In the reviewed studies, this total score was also used to evaluate these questionnaires, which contradicts the original intention of a symptom-specific approach. Furthermore, as they comprise only one item per symptom domain, no subscales can be calculated and it is therefore not possible to determine some aspects of reliability, i.e., internal consistency. However, the $R M I$ and its related questionnaire $R M Q$ as well as the EDSOCQ constitute exceptions to these aspects, as the authors calculate separate scores for each subscale and provide information on the psychometric properties of each of the subscales. Nevertheless, the ANSOCQ and BNSOCQ are useful tools in practice for planning treatment, as they allow an insight into motivation concerning different eating disorder symptoms.

Measures provided in a questionnaire format are widespread as they provide an economical and reliable method of measurement. They are easy to administer, require little or no training, and are less time-consuming than interviews. However, they also have some disadvantages compared to interviews such as the $R M I$ [28], especially concerning the validity in an ambivalent clientele like women with eating disorders [51]. The use of questionnaires to measure the stages of change has been criticised due to oversimplification and the danger of alienating patients [52]. To prevent misunderstandings while filling out questionnaires, and in order to build a more collaborative therapeutic relationship [53], an interview procedure like the $R M I$ seems to be highly suitable if a time-consuming application is possible. However, most studies on motivation to change in eating disorders conducted to date exclusively applied questionnaires [4,9,50,54-57] and many $[4,58]$ used the University of Rhode Island Change Assessment Scale (URICA [59,60]), which is not specifically addressed at patients with eating disorders but rather at problem behaviours in general. Moreover, the URICA can be criticised for measuring motivation to change a problem behaviour in general terms and not in a symptom-specific manner with each symptom domain being assessed separately [26]. For a more detailed investigation of motivation to change in eating disorders, it can be recommended that in future research, more precise symptom- and disorderspecific instruments should be used, such as the RMI, $R M Q$, and EDSOCQ.

One of the most important features of an instrument measuring motivation to change is probably that it predicts readiness to make changes. Concerning their predictive utility, the $R M I, R M Q$, and ANSOCQ have proven most beneficial, as their relative ability to predict clinical outcome temporally has received the best support so far. The ANSOCQ has proven to be a useful tool in this regard, as it predicts weight gain during treatment [22], while lower motivation scores on the $R M I$ at baseline were associated with treatment dropout after 12-15 weeks [20]. Furthermore, both $R M I$ and $R M Q$ scores predicted completion of recovery activities over time [20,21,28]. Evidence has also been found concerning the prediction of clinical outcomes from a cross-sectional perspective for these three measures, while support for the predictive validity of all other reviewed instruments is so far lacking.

In spite of the current lack of predictive clinical utility of decisional balance scales, the potential role of these assessment tools in treatment planning should be nevertheless considered. The $D B, P$-CAN, and $P$-CED may be useful for therapists to gain an insight into the pros and cons of an eating disorder as perceived by the patient, especially concerning the maintenance of the disorder. 
Research conducted to date suggests that there are qualitative differences between patients with anorexia and bulimia nervosa regarding their arguments for and against their disorder [1]. Moreover, patients suffering from anorexia nervosa seem to be less motivated for behavioural change than those with bulimia nervosa [4]. Thus, the diagnosis-specific questionnaires $A N S O C Q, D B, P$-CAN, and $B N S O C Q$ are suitable for diagnostically homogeneous populations consisting of patients with anorexia or with bulimia nervosa. However, in order to compare the differences regarding the extent of motivation to change between patients with various eating disorder diagnoses, measurements such as the EDSOCQ, MSCARED, RMI, RMQ, or $P$-CED are useful tools. They are therefore more in line with the transdiagnostic model of eating disorders [61].

It has to be taken into consideration that all of the assessment tools reviewed here are based on the TTM. Although the TTM has been successfully applied to a number of health problems and there is a large body of research supporting its assumptions [13,62], it has been criticised concerning several aspects [63]: Due to the categorical nature of this model, critics point out that motivation to change might be better measured on a continuum rather than in distinct categories and that the stages do not constitute discrete categories because it is possible for individuals to be in more than one stage at the same time. However, to date, the research literature does not provide any alternative solution to this categorical model and the categorical assessment approach. In contrast to the theory based on categories, statistical analyses are sometimes not based on ordinal-scaled variables. Data are rather interpreted as interval-scaled instead, which acts on the assumption of a dimensional model and no distinct categories. If the TTM is not a valid model, the instruments derived from it may not be valid either. Thus, ideally, future research should develop dimensional approaches in measuring motivation to change as a continuum and compare them with previous tools, especially in terms of their validity. However, the TTM has proven to be useful in clinical research and practice [63], and significant relationships between initial stage of change and treatment outcome have been demonstrated in the eating disorders in several, but not all, studies [13].

Finally, this review is subject to the limitation that only published literature was included. It is not uncommon for unpublished and non-validated scales to be used for investigation purposes. These unpublished assessment tools were not reviewed here as it was not possible to systematically identify them through the literature search.

To conclude, the TTM, which has been criticised due to its categorical assumptions, offers the only theoretical framework so far for tools which assess motivation to change in eating disorders. Nevertheless, psychometric properties of the identified instruments are satisfactory to good. All assessment tools have specific benefits and burdens and the selection of a specific instrument depends on the context of assessment. Overall, the $R M Q$ and $R M I$ in particular fulfil important aspects of an instrument measuring motivation to change in eating disorders, as they measure the construct in a symptom-specific way, allow the calculation of subscales for different symptom domains, can be applied to heterogeneous groups, and provide predictive utility. The $R M Q$, as a questionnaire, is rather economical, less time-consuming, reliable, and easy to apply, while the $R M I$, as an interview, requires time and training but might be most valid and helpful in order to build a collaborative relationship for treatment.

\section{Competing interests}

The authors declare that they have no competing interests.

\section{Authors' contributions}

All authors contributed to the development of this review and drafted the manuscript. KH carried out the literature search. All authors read and approved the final manuscript.

\section{Acknowledgements}

This work was supported by the German Research Foundation (DFG), Grant No. VO1750/1-1.

Received: 17 May 2013 Accepted: 29 September 2013

Published: 10 October 2013

\section{References}

1. Schmidt U, Treasure J: Anorexia nervosa: valued and visible: A cognitiveinterpersonal maintenance model and its implications for research and practice. Br J Clin Psychol 2006, 45(3):343-366.

2. Serpell $L$, Treasure J: Bulimia nervosa: friend or foe? The pros and cons of bulimia nervosa. Int J Eat Disord 2002, 32(2):164-170.

3. Treasure J, Katzman M, Schmidt S, Troop N, Todd G, de Silva P: Engagement and outcome in the treatment of bulimia nervosa: first phase of a sequential design comparing motivation enhancement therapy and cognitive behavioural therapy. Behav Res Ther 1999, 37(5):405-418.

4. Casasnovas C, Fernández-Aranda F, Granero R, Krug I, Jiménez-Murcia S, Bulik CM, Vallejo-Ruiloba J: Motivation to change in eating disorders: clinical and therapeutic implications. Eur Eat Disord Rev 2007, 15(6):449-456.

5. Waller $\mathrm{G}$ : The myths of motivation: time for a fresh look at some received wisdom in the eating disorders? Int J Eat Disord 2012, 45(1):1-16.

6. Bandini S, Antonelli G, Moretti P, Pampanelli S, Quartesan R, Perriello G: Factors affecting dropout in outpatient eating disorder treatment. Eat Weight Disord 2006, 11(4):179-184

7. DeJong $H$, Broadbent $H$, Schmidt U: A systematic review of dropout from treatment in outpatients with anorexia nervosa. Int J Eat Disord 2012, 45(5):635-647

8. Wade TD, Frayne A, Edwards SA, Robertson T, Gilchrist P: Motivational change in an inpatient anorexia nervosa population and implications for treatment. Aust N Z J Psychiatry 2009, 43(3):235-243.

9. Castro-Fornieles J, Bigorra A, Martínez-Mallen E, Gonzalez L, Moreno E, Font E, Toro J: Motivation to change in adolescents with bulimia nervosa mediates clinical change after treatment. Eur Eat Disord Rev 2011, 19(1):46-54.

10. Bardone-Cone AM: Examining the match between assessed eating disorder recovery and subjective sense of recovery: Preliminary findings. Eur Eat Disord Rev 2012, 20(3):246-249.

11. Mansour S, Bruce KR, Steiger H, Zuroff DC, Horowitz S, Anestin AS, Sycz L: Autonomous motivation: a predictor of treatment outcome in bulimiaspectrum eating disorders. Eur Eat Disord Rev 2012, 20(3):116-122.

12. Knowles $L$, Anokhina $A$, Serpell $L$ : Motivational interventions in the eating disorders: what is the evidence? Int J Eat Disord 2013, 46(2):97-107.

13. Dray J, Wade T: Is the transtheoretical model and motivational interviewing approach applicable to the treatment of eating disorders? A review. Clin Psychol Rev 2012, 32(6):558-565. 
14. Munõz P, Quintana J, Las Hayas C, Padierna A, Aguirre U, Gonzalez-Torres MA: Quality of life and motivation to change in eating disorders: perception patient-psychiatrist. Eat Behav 2012, 13(2):131-134.

15. Geller J: What a motivational approach is and what a motivation approach isn't: reflections and responses. Eur Eat Disord Rev 2002, 10(3):155-160.

16. Prochaska JO, DiClemente CC: Stages of change in the modification of problem behaviors. In Progress on behavior modification. Edited by Hersen M, Eisler RM, Miller P. Sycamore, IL: Sycamore; 1992:184-214.

17. Janis IL, Mann L: Decision making: a psychological analysis of conflict, choice, and commitment. New York: Free Press; 1977

18. Fisseni HJ: Lehrbuch der psychologischen Diagnostik: Mit Hinweisen zur Intervention. Göttingen: Hogrefe; 1997

19. Geller J, Drab DL: The readiness and motivation interview: a symptomspecific measure of readiness for change in the eating disorders. Eur Eat Disord Rev 1999, 7(4):259-278.

20. Geller J, Cockell SJ, Drab DL: Assessing readiness for change in the eating disorders: the psychometric properties of the readiness and motivation interview. Psychol Assessment 2001, 13(2):189-198.

21. Geller J, Brown KE, Zaitsoff SL, Menna R, Bates ME, Dunn EC: Assessing readiness for change in adolescents with eating disorders. Psychol Assessment 2008, 20(1):63-69.

22. Rieger E, Touyz S, Schotte D, Beaumont P, Russel J, Clarke S, Kohn M Griffiths R: Development of an instrument to assess readiness to recover in anorexia nervosa. Int J Eat Disord 2000, 28(4):387-396.

23. Rieger E, Touyz SW, Beumont PJV: The anorexia nervosa stages of change questionnaire (ANSOCQ): information regarding its psychometric properties. Int J Eat Disord 2002, 32(1):24-38.

24. Serrano E, Castro J, Ametller L, Martínez E, Toro J: Readiness to recover in adolescent patients with anorexia nervosa. Psychol Psychother 2004, 77(1):91-99.

25. Martínez E, Castro J, Bigorra A, Morer A, Calvo R, Vila M, Toro J, Rieger E: Assessing motivation to change in bulimia nervosa: the bulimia nervosa stages of change questionnaire. Eur Eat Disord Rev 2007, 15(1):13-23.

26. Ackard DM, Croll JK, Richter S, Adlis S, Wonderlich A: A self-report instrument measuring readiness to change disordered eating behaviors: the eating disorders stage of change. Eat Weight Disord 2009, 14(2-3):66-76.

27. Gusella J, Butler G, Nichols L, Bird D: A brief questionnaire to assess readiness to change in adolescents with eating disorders: Its applications to group therapy. Eur Eat Disord Rev 2003, 11(1):58-71.

28. Geller J, Brown KE, Srikameswaran S, Piper W, Dunn EC: The psychometric properties of the readiness and motivation questionnaire: a symptomspecific measure of readiness for change in the eating disorders. Psychol Assess 2013, 25(3):759-768

29. Cockell SJ, Geller J, Linden W: The development of a decisional balance scale for anorexia nervosa. Eur Eat Disord Rev 2002, 10(5):359-375.

30. Cockell SJ, Geller J, Linden W: Decisional balance in anorexia nervosa: capitalizing on ambivalence. Eur Eat Disord Rev 2003, 11(2):75-89.

31. Serpell L, Teasdale JD, Troop NA, Treasure J: The development of the PCAN, a measure to operationalize the pros and cons of anorexia nervosa. Int J Eat Disord 2004, 36(4):416-433.

32. Serpell L, Neidermann M, Haworth E, Emmanueli F, Lask B: The use of the pros and cons of anorexia Nervosa (P-CAN) Scale with children and adolescents. J Psychosom Res 2003, 54(6):567-571.

33. Gale C, Holliday J, Troop NA, Serpell L, Treasure J: The pros and cons of change in individuals with eating disorders: a broader perspective. Int J Eat Disord 2006, 39(5):394-403.

34. Beck AT, Steer RA, Ball R, Ranieri W: Comparison of beck depression inventoriesIA and -II in psychiatric outpatients. J Pers Assess 1996, 67(3):588-597.

35. Cooper PJ, Taylor MJ, Cooper Z, Fairburn CG: The development and validation of the body shape questionnaire. Int J Eat Disord 1987, 6(4):485-494.

36. Kovacs M: Children's depression inventory manual. North Tonawanda, NY: Multi-Health Systems, Inc; 1991

37. Vitousek K, de Viva J, Slay J, Manke F: Concerns about change in the eating and anxiety disorders. New York: Paper presented at the annual meeting of the American Psychological Association; 1995.

38. Fairburn CG, Beglin SJ: Assessment of eating disorders: Interview or selfreport questionnaire? Int J Eat Disord 1994, 16(4):363-370.

39. Garner DM, Olmsted MP, Polivy J: Development and validation of a multidimensional eating disorder inventory for anorexia nervosa and bulimia. Int J Eat Disord 1983, 2(2):15-34

40. Garner DM: Eating Disorder Inventory-2: Professional manual. Odessa, Florida: Psychological Assessment Resources; 1991.
41. Prochaska JO, DiClemente CC: Stages and processes of self-change in smoking: toward an integrative model of change. J Consult Clin Psychol 1983, 52(3):390-395.

42. Paulhus DL: Reference manual for BIDR Version 6. Vancouver, Canada: University of British Columbia; 1994.

43. Reynolds WE: Development of reliable and valid short forms of the marlowe-crowne social desirability scale. J Clin Psychol 1982, 38(1):119-125.

44. Crandall VC, Crandall VJ, Katovsky W: A children's social desirability questionnaire. J Consult Psychol 1965, 29(1):27-36.

45. Rossi JS, Rossi SR, Velicer WF, Prochaska JO: Motivational readiness to control weight. In Handbook of assessment methods for eating behaviors and weight-related problems. Edited by Allison DB. London: Sage; 1995:387-430.

46. Serpell L, Treasure J, Teasdale J, Sullivan V: Anorexia nervosa: friend or foe? Int J Eat Disord 1999, 25(2):177-186.

47. Rieger $E_{1}$ Touyz $S$ : An investigation of the factorial structure of motivation to recover in anorexia nervosa using the anorexia nervosa stages of change questionnaire. Eur Eat Disord Rev 2006, 14(4):269-275.

48. Dunn EC, Neighbors C, Larimer ME: Assessing readiness to change binge eating and compensatory behaviors. Eat Behav 2003, 4(3):305-314.

49. Perkins S, Schmidt U, Eisler I, Treasure J, Berelowitz M, Dodge E, Frost S, Jenkins $M$, Johnson-Sabine E, Keville $S$, Murphy R, Robinson P, Winn S, Yi I: Motivation to change in recent onset and long-standing bulimia nervosa: are there differences? Eat Weight Disord 2007, 12(2):61-69.

50. Katzman MA, Bara-Carril N, Rabe-Hesketh S, Schmidt U, Troop N, Treasure J: A randomized controlled two-stage trial in the treatment of bulimia nervosa, comparing CBT versus motivational enhancement in phase 1 followed by group versus individual CBT in Phase 2. Psychosom Med 2010, 72(7):656-663.

51. von Wietersheim J, Hoffmann C: Erhebungsinstrumente zur Veränderungsmotivation von Patientinnen mit Anorexia nervosa im Vergleich. Z Psychosom Med Psyc 2011, 57(1):62-76.

52. Sullivan V, Terris C: Contemplating the stages of change measures for eating disorders. Eur Eat Disord Rev 2001, 9(5):287-291.

53. Miller WR, Rollnick S: Motivational interviewing: Preparing people for change. 2nd edition. New York: Guilford; 2002

54. Allen KL, Fursland A, Raykos B, Steele A, Watson H, Byrne SM: Motivationfocused treatment for eating disorders: a sequential trial of enhanced cognitive behaviour therapy with and without preceding motivationfocused therapy. Eur Eat Disord Rev 2012, 20(3):232-239.

55. Feld R, Woodside DB, Kaplan AS, Olmsted MP, Carter JC: Pretreatment motivational enhancement therapy for eating disorders: a pilot study. Int J Eat Disord 2001, 29(4):393-400.

56. George L, Thornton C, Touyz SW, Waller G, Beaumont PJV: Motivational enhancement and schema-focused cognitive behavior therapy in the treatment of chronic eating disorders. Clin Psychol 2004, 8(2):81-85.

57. Gowers SG, Smyth B: The impact of a motivational assessment interview on initial response to treatment in adolescent anorexia nervosa. Eur Eat Disord Rev 2004, 12(2):87-93.

58. Hasler G, Delsignore A, Milos G, Buddeberg C, Schnyder U: Application of Prochaska's transtheroretical model of change to patients with eating disorders. J Psychosom Res 2004, 57(1):67-72.

59. McConnaughy EA, Prochaska JO, Velicer WF: Stages of change in psychotherapy: measurement and sample profiles. Psychother Theory Res Pract 1983, 20(3):368-375.

60. McConnaughy EA, DiClemente CC, Prochaska JO, Velicer WF: Stages of change in psychotherapy: a follow-up report. Psychother 1989, 26(4):494-503.

61. Fairburn CG, Cooper Z, Shafran R: Cognitive behaviour therapy for eating disorders: a 'transdiagnostic' theory and treatment. Behav Res Ther 2003, 41(5):509-528.

62. Norcross JC, Krebs PM, Prochaska JO: Stages of change. J Clin Psychol 2011, 67(2):143-154

63. Wilson GT, Schlam TR: The transtheoretical model and motivational interviewing in the treatment of eating and weight disorders. Clin Psychol Rev 2004, 24(3):361-378.

doi:10.1186/2050-2974-1-38

Cite this article as: Hötzel et al:: Assessing motivation to change in eating disorders: a systematic review. Journal of Eating Disorders 2013 1:38. 